\title{
Optical Measurement of Preselected Individual Body Parameters, 3D Curves and Belt Position for Garment Manufacturing and Sales with BodyFit 3D
}

\author{
Lars KUNZE, Niels HEUWOLD, Lothar PAUL \\ Gesellschaft zur Förderung angewandter Informatik e.V. Berlin (GFal)*, Berlin, Germany
}

\begin{abstract}
We present a solution for recording individual body parameters, targeting cost effective custom garment manufacturing. Different from alternative scanning solutions, just pre-selected crucial body parameters and 3d-curves are measured with BodyFit 3D, but these measures are taken in fractions of a second so that clients are not confronted with demands for holding a certain position for long. Additionally, as one of several extensions, a newly integrated measurement belt allows to take individual wearing habits into account.
\end{abstract}

Keywords: $3 d$ body measurement, body parameters, body size, BodyFit 3D, garment manufacturing, mass costumization

\section{Introduction}

\subsection{Challenges of modern individual garment manufacturing}

Without doubt, garment manufacturers face huge challenges in regard of both the immense pricing pressure coming from competitors in mass production and the actual demands of mass customization and product individualization. Besides traditional garment production in standard sizes on the one and tailor-made suits on the other hand, step-by-step new forms of manufacturing emerge, targeting industrial made-to-measure garment.

For both women and men the process of choosing a clothing product includes a lot of individual preferences (style, fashion, colours), but one of the basic demanded and most natural features remains a correct fit to ones own body which in turn presupposes evaluation or measurement of this body and adequate technologies for parametric (desirably automated) pattern adaptation. Our following contribution deals with some particular aspects and solutions for recording individual body parameters.

In classic customized manufacturing by tailors body measurement, pattern design and manufacturing lay in one hand and responsibility. In case of an industrial background that changes fundamentally: here, measure acquisition and production are often geographically and organizationally separated, and pattern construction may be performed completely by external services. The typical location for acquiring the necessary client body measures nowadays are well-patronised facilities like trade areas, where the technical measurement equipment is potentially usable for several producers .

Hence, a basic requirement for successful industrial customized clothing production becomes the definition of the "necessary and sufficient" parameter set that leaves no room for ambiguous interpretations and the agreement of consistent criteria and rules for their practical measurement. Unlike typical technical measurement tasks, this part turns out to be a complex challenge, if there are different manufacturers and garment specialists involved. Seen from an isolated metrology viewpoint, these efforts can be avoided by approaches providing a complete and redundant geometry measurement of the whole body. Then, separation, interpretation, selection and parametrization of the resulting data are delegated to subsequent operations or algorithms. This is the case with whole-body laserscanners, for example, whereat the measurement procedure provides a complete threedimensional representation (snapshot) of the body. The parameters, finally required for twodimensional pattern design, must be derived subsequently by algorithmic processing or interactively by an operator.

Deliberately we chose a different approach for our solution BodyFit $3 D$. Our aim was the implementation of a targeted, selective measurement of predefined local $3 \mathrm{~d}$ body features and the calculation of parameters compatible to pattern design programs, performed with a low-priced, practicable and automatic measuring station.

* www.gfai.de/forschungsbereiche/3d/3ddv/ 


\subsection{Advantage of optical automated body measurement}

One of the indisputable advantages of automatic data acquisition is that body measurements are determined objectively and everywhere, every time the same way. Experience shows that both manual-interactive analysis of scanning data and manual measurements performed by different people (even tailors) lead to significant deviations which are founded subjectively and can be avoided by automatic measurement. Though, as mentioned before, in special cases subjective and very individual data interpretation may lead even to a more appropriate final result with a highly experienced and qualified person in charge, but only if that person will be able to influence pattern adjustment and production too. Unfortunately, in the context of industrial garment manufacturing such conditions are not typical and often not realistic.

In mail-order and internet businesses clients are usually suggested to take their measures themselves by a given set of instructions. Here too, but to a larger degree the arguments given above apply, resulting in large amounts of return consignments.

For most people manual body measurement by another person turns out to be a quite intimate and particularly delicate issue. Our experience shows, that automated optical measurement approaches are easily accepted by garment clients and even the necessity of undressing in a closed cabin (equipped with cameras) does not evoke big objection, if the provider explicitly and accountably declares that any misuse is excluded.

Furthermore, automatic sensor based recording of body measurements allows to identify and to include several body parameters which cannot be defined by traditional manual measurement (e.g. angles and diameters). It becomes possible to take into account, for example, shoulder angles for pattern design of shirts and jackets.

\subsection{Application demands to body measurement and parametrization}

Speaking about industrial made-to-measure garment producers in Germany and probably in Western Europe means dealing mostly with SME, which provide their products to much larger trading chains and business enterprises [6].

Beside this, a rewarding client segment can be identified in the area of corporate fashion (hotels, airlines, police, uniforms etc.). As far as most manufacturers cannot afford expensive capital investments, any form of association and cost sharing with dealers, warehouses and other producers should be highly welcome in order to push new customization oriented technologies, though currently this seems to be difficult to achieve in practice. From this point of view, economic requirements to body measurement solutions are a low investment level, provision of financing and leasing models, high reliability together with a high degree of automation and low maintenance expenses. (Unfortunately, all of this is not typical for the phase of product development and market launch).

Other application specific and technical requirements to body measurement solutions are seen in

- Compatibility with existing and available CAD pattern construction systems

- Exact and automatic recording of the desired body measures (which may differ from case to case)

- Short measurement time (to avoid measurement failures from blurring, breathing and client motions)

- Absolute safety

- Flexible layout and portability, compactness

- Mobile versions

\section{Description of method and basic measurement system BodyFit 3D}

\subsection{Concept, measurement flow and features}

Differently from alternative solutions, BodyFit $3 D$ measurement is not based on a mechanical scanning procedure and no kind of moving machine part is involved here. Even fast scanning procedures would require a certain time of torpor in the scene, which is not necessary with the presented solution.

BodyFit 3D measurement does not aim at the acquisition of whole-body models. Instead, a predefined set of individual, three- and two-dimensional parameters is taken. During a measurement procedure of about 1,5 minutes, which proceeds in a relaxed atmosphere, about 100 predefined parameters (numbers) are taken or calculated automatically, wherein the single measures come from short image shots $(0.5 \mathrm{sec})$. If necessary, further particular measures and parameters may be derived from the captured data. The typical accuracy of the single measures is in the range of 5 to $10 \mathrm{~mm}$. 
The functional layout of BodyFit $3 D$ systems is given in fig. 1. The measurement flow is based on a combined approach of contour analysis and light-section measurement. After recognition of body tallness and some distinctive contour points, an individually structured light pattern is projected exactly to the body regions of interest. The local deformation of these pattern is analyzed and interpreted to derive the three-dimensional body surface characteristics. The equipment exclusively uses white light, so health-related concerns about laser influence and security restrictions are avoided completely.

Control of the BodyFit $3 D$ cabin workflow is completely automatic and no direct action of client or service personal is involved. Though no conscious control activity is required, the clients behavior influences speed and flow of events in an indirect way. Having entered a BodyFit $3 D$ cabin, a client is given a welcome and is introduced to some basic rules. After preparation, the client is asked to betake himself onto the platform and to further follow the given acoustic and visual instructions in order to take the required five different postures for measurement. When the system detects the achievement of suitable position and posture, the client is asked to hold this position for a moment. Then, the achievable measures are taken very quickly in a fraction of a second. That means, the client should not "freeze" to hold his posture for long in each of the required five postures like that is the case with alternative scanning solutions. The danger of measurement errors from "shaking", breathing or involuntary motion is significantly minimized or excluded.

Crucial for accurate operation and measurement flow is a complete exclusion of extraneous light sources, that means a $100 \%$ control of light conditions inside the cabin. As far as body measurement procedures obviously require the proband to act in (desirably wrinkle-free) underwear only, a sealing from external glances is required anyway. For that matter it was reasonable to arrange the complete equipment, together with enough space for changing, in closed, light-tight cabin constructions (see also 2.6.).

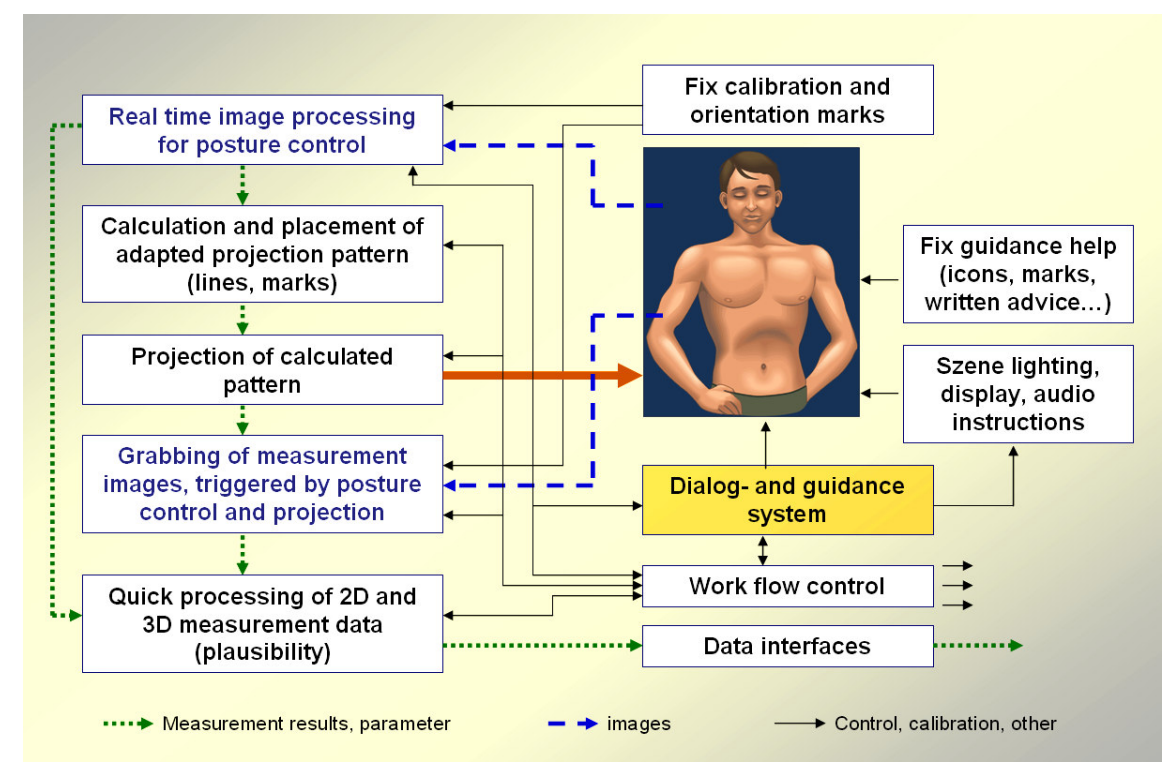

Fig. 1: Functional layout of the BodyFit 3D measurement system for contactless body parameter acquisition

\subsection{Hardware components}

A measurement kernel of BodyFit 3D systems consists of the following hardware components:

Two digital cameras serve as image sensors, a commercially obtainable beamer is used for controlled pattern projection. The usage of such standard hardware modules may count as another advantage of the BodyFit 3D solution, since it decreases the necessary capital investment. For calibration purposes a calibration rack with optical marks, which is approximately the size of a human torso is necessary and provided. This equipment is used solely in the system installation stage or for regular maintenance.

Image sensors and projecting device are mounted and fixed behind a vertical wall, which separates the client area from a small technical section. In static cabin layouts, respectively after assembling the modules in dismountable layouts (see 2.6.) just a short and widely automated calibration procedure is needed to prepare the measurement kernel for it's task. 
In a fixed distance from the back lighting wall, which is located opposite to the sensors, a flat platform (part of the dialog system) is integrated in the cabin floor, on which the proband is offered to perform the five different prescribed measurement postures after his personal preparation is finished. The large-area, controlled and dimmable backlighting ("light wall"), located behind the client is another important part of the measurement system, and serves for contour tracking facilitation (online position control).

A standard PC with additional serial interfaces is used to control both measurement and the dialog system (see 2.3.), which generates and transmits optical and acoustical assistance instructions and corrections for the client inside the cabin.

\subsection{Dialog system}

The integrated dialog system itself is not involved in optical measurement, but is designed to ensure a comprehensible, save and unambiguous action flow during the clients abidance in the cabin. It consists of loudspeakers, the active platform, a flat screen visible to the client and some additional static signs, depictions (pictograms) inside the cabin and, of course, the dialog software. It leads the probands through the complete cycle from entering to leaving the cabin.

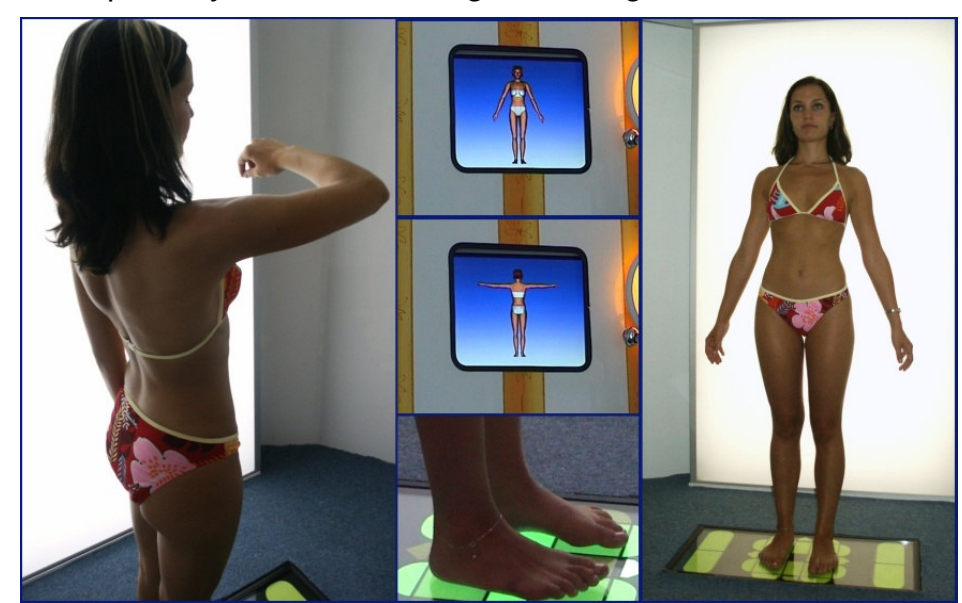

Fig. 2: Elements of the dialog system: cabin-integrated flat screen, active platform

Apart from some verbal salutation, introduction, basic hints and even a bit background music while a client prepares, dresses or undresses, the acoustic system advices the client regarding the ongoing event. Especially this is related to the explanation of the five different postures which are inevitable for recording girth parameters. Three language versions (German, English and Czech) are available at the moment.

The spoken explanations are supported by pictures and clips on the cabin-integrated flat screen. The platform on which the person is expected to stand, is equipped with active optical signs indicating the actual needed position. The dialog system receives information about the client's position and posture both from the online image processing and platform and is able to generate a number of situation dependent correction hints. This ensures a suitable and sufficient posture of the client for the outstanding measurement. (see fig. 2, 3)
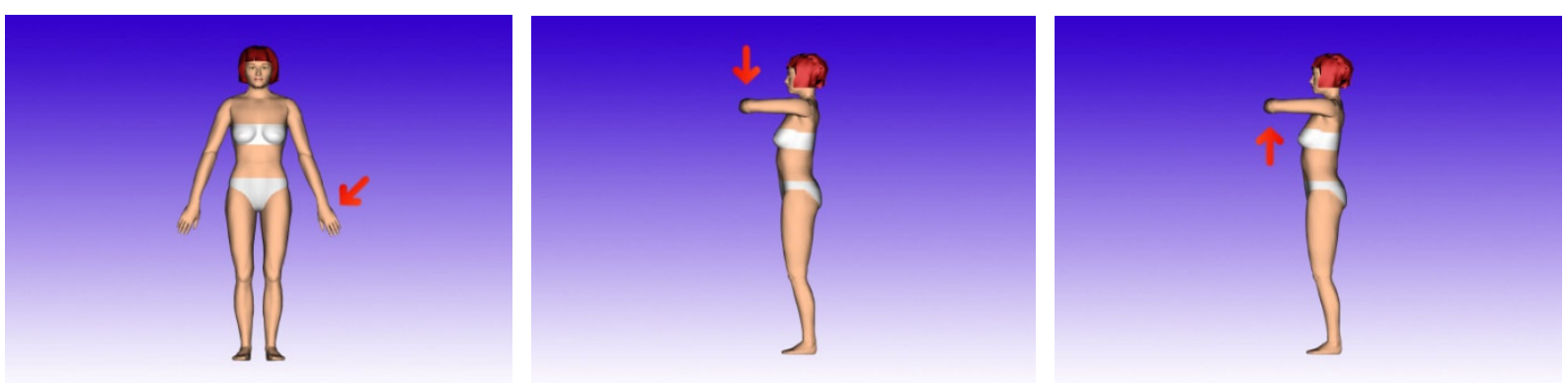

Fig. 3: Screenshots from the cabin-integrated screen, advising the client to correct posture 


\subsection{Measurement results and output}

As already mentioned, the standard output of the BodyFit $3 D$ system consists of about 100 numeric parameters, the most important (30) of which are printed on a client sheet directly in the cabin. The other, together with a set of more detailed curves (polylines) from the client's body surface, are stored or directly transferred to a destination server (cf. fig.4). Another option, notably interesting for marketing aspects is to save the measurement results on a client chip cart, enabling that person to purchase particular made-to-measure garment models from participating shops or per internet order.

Parametric pattern design programs usually require solely numeric input (individual measure tables) and may be easily supported by completely compatible output generated by BodyFit 3D. Output table format adaptation is currently available for two existing design programs (NovoCut Maßkonstruktion, Grafis). Beyond tables, the more detailed geometric information can be used for visual control or evaluation in this case. Anyway, the detailed curvature information turns out to be very helpful in other applications like body modeling (see system extensions section 3.3.).
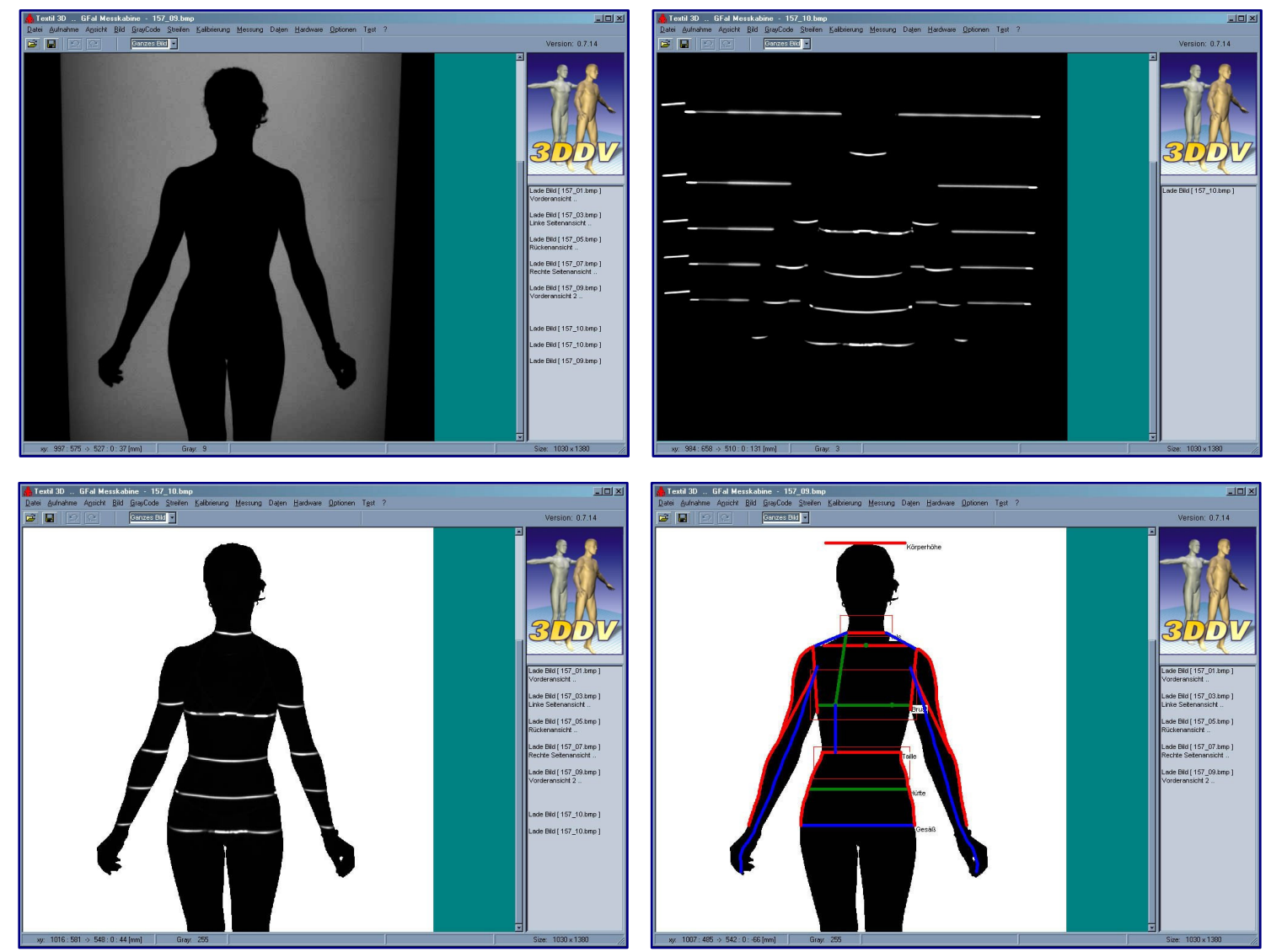

Fig. 4: Screenshots, illustrating a selective single-shot 3D measurement (contour tracking, local stripe projection and calculated parameters)

As far as images of the client's body can be captured only from one side during each measurement step, reliable calculation of girth measures has been a non-trivial challenge. The acquired curvature segments, taken one after the other in different postures of the proband, are initially not fitted in a common coordinate system. So, for increased reliableness all girth measures are calculated using two independent algorithmic approaches, which are based on plane transformations and local curvature analysis respectively. To achieve comparability to standard girth measures, the fitted curves are further transformed into envelops by eliminating all concavities (fig. 5). 

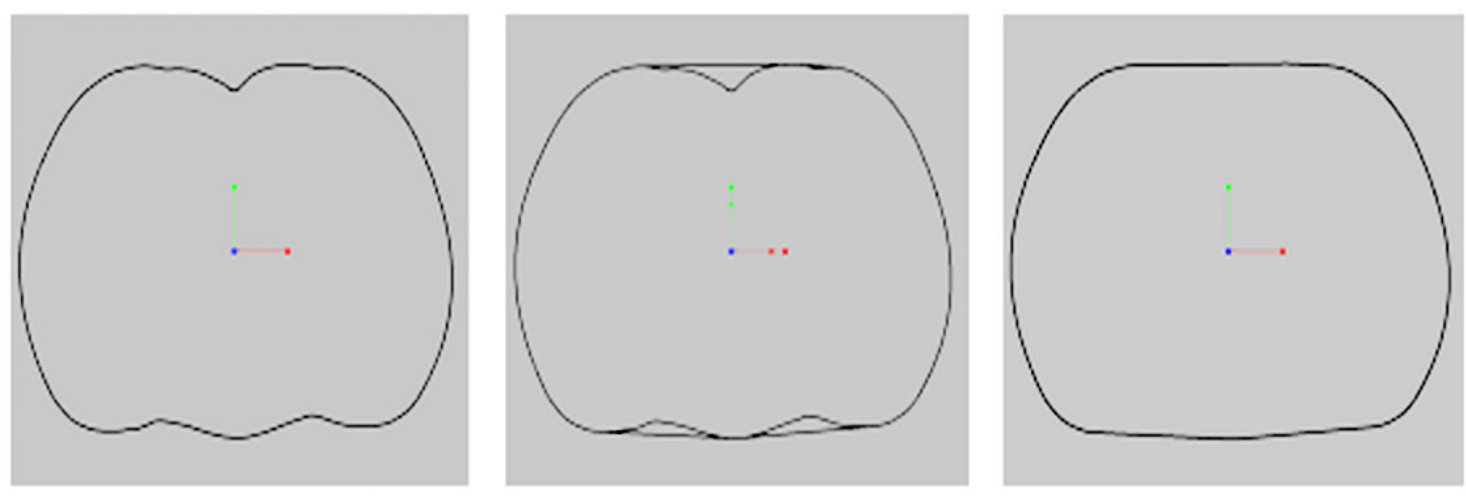

Fig. 5: fitted buttock girth curves and derivation of envelop measure (elimination of concavities)

\subsection{System layout}

Dependent on concrete application target and budget, BodyFit 3D systems can be built and arranged in different layout variants.

As an example may serve a completely mobile layout (fig. 6) of the Saxon firm Lobe Wäsche P. Kunze, arranged inside a trailer. Such a layout enables the owner to offer on-site measurement at the client's place, which is advantageous for corporate fashion clients or in rather rural areas.

Alternative layout variants provide fix installation inside a dismountable outer cabin construction or even inside available building rooms or cubicles, after slight constructional adaptation. As long as the general module configuration and system demands are met, the cabin layout can be varied to meet the user's standards.

The required footprint area is in the range of approximately 4 to 2,5 meters, recommended height is $>2.2 \mathrm{~m}$.
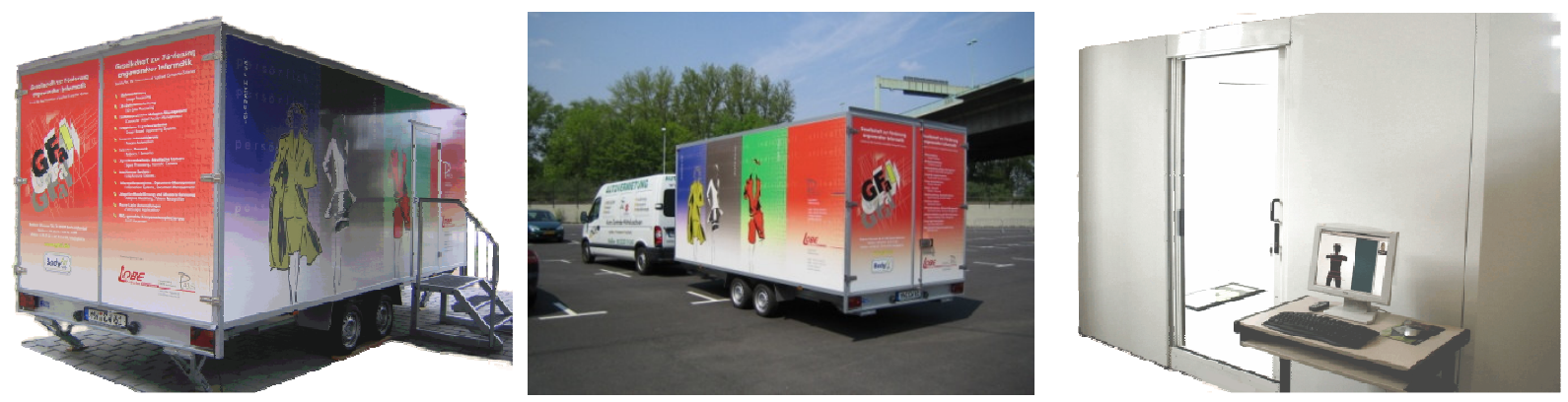

Fig. 6: Mobile and stationary layouts of BodyFit 3D cabins

\section{Description BodyFit 3D system extensions}

\subsection{Inclusion of individual wearing habits (measurement belt)}

As a newly implemented extension of the BodyFit 3D system we introduce the possibility to digitize individual wearing habits or preferences of a client (to a certain degree), particularly targeting the segment of trousers and shorts. This, of course, represents a deviation from the general philosophy of an uniform and objective body parametrization, because it means to admit a user dependent subset of measures into the common list. But on the other hand such extension is a useful tool in cases, where the workflow allows to respond to the individuality of clients in more detail [cf. 1]. Furthermore, if full measurement flow automation is not of first priority, the approach potentially allows to support established measure traditions and to enlarge the standard output list by self-defined parameters. 

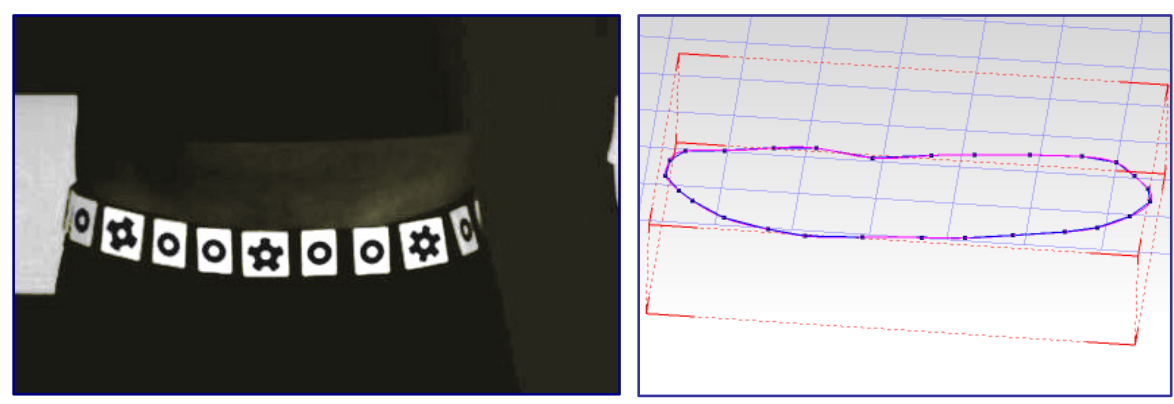

Fig. 7: Optical 3D belt measurement:

left: front view image of proband wearing a measurement belt, captured in the cabin right: the preferred waistband line derived from four measurements

For recording of individual preferences, a set of textile measure belts is used. A client will apply one of these flexible belts inside the cabin like an usual trouser belt, and position it at his preferred waistband location. The measurement belts are equipped with optically identifiable marks. The three-dimensional position of that marks is recorded during the standard measurement flow. After fitting and sequencing the identified coordinates, a spline curve is calculated which clearly identifies the desired waistband position (Fig 7) and, hereby, one of the clients individual preferences.

\subsection{Flexible and weighted size determination for garment sale: BodySizer}

To make wider use of BodyFit measurement results even beyond pattern construction and made-to measure products, the application program BodySizer was developed as an extension or stand-alone version. It can be used for flexible determination of best-fit garment table sizes based on the measurement cabin output.

It must be mentioned, that underlying size tables of most producers and trade chains significantly differ for several reasons and that one cannot rely on size numbers affirmed during a certain purchase.

The BodySizer program allows to import (and to edit) size tables of different manufacturers or labels. Furthermore, it offers the possibility to weight or prioritize each available measure parameter regarding it's significance for size determination.

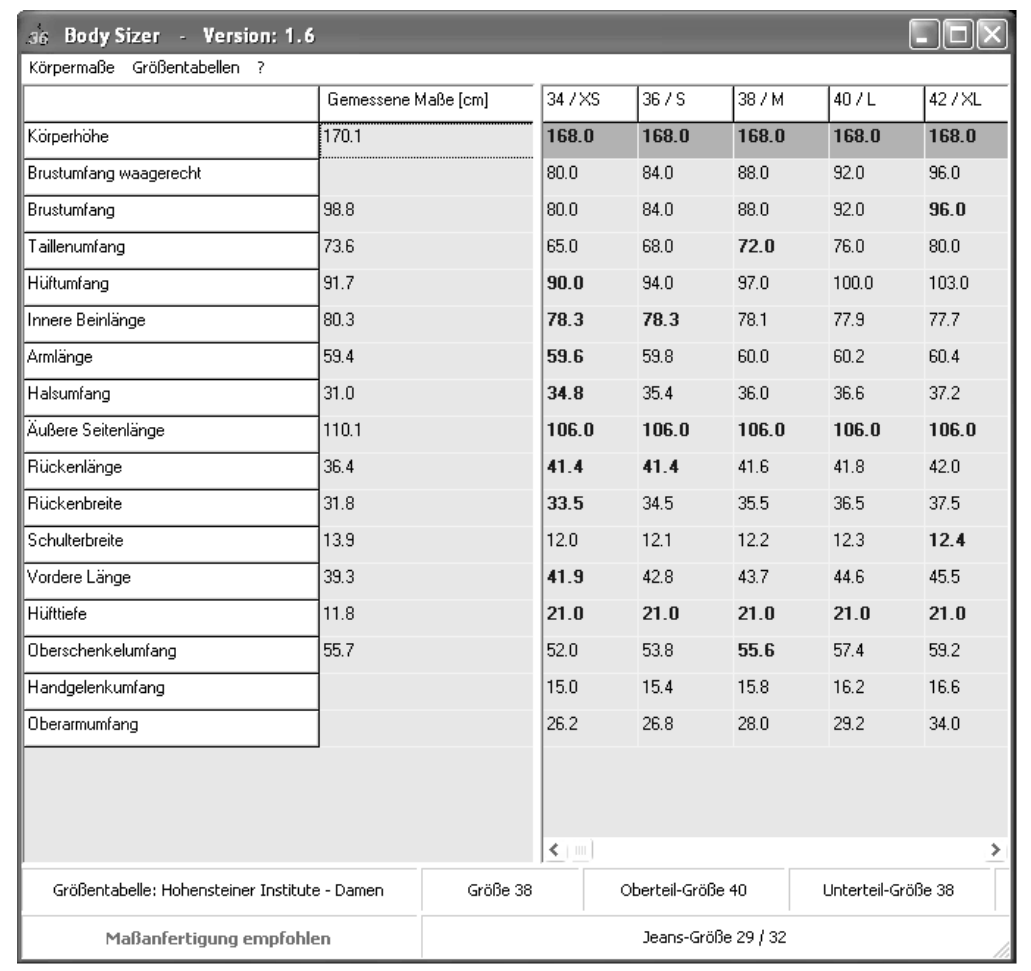

Fig. 8: BodySizer imports BodyFit 3D data to calculate weighted size measures. 
The program user loads, for example, his personal measure record from BodyFit $3 D$ and the size table of his favourite fashion provider (fig. 8). He is able to prioritize or weaken the influence of some measures and to get the target table size of his selected piece of garment. The program provides size specifications separately for upper or lower garment parts (as jackets and trousers). Another possibility is the determination of the best fitting standard size among all registered size tables (from different garment manufacturers). This way the BodySizer software can be useful in retail for quick selection of ready-made clothing pieces, independent from or supplementary to made-to-measure offers in a certain trade segment.

\subsection{Individual $3 \mathrm{~d}$ body models (3d avatars)}

The BodyFit $3 D$ systems do not perform whole-body scans, as already mentioned in section 2.1, but provide geometrical information selectively. However, several potential applications like garment product preview, virtual design assistance, advertisement and $3 \mathrm{~d}$ garment construction tools require individual $3 \mathrm{~d}$ body models. In order to address such application fields, another extension to BodyFit $3 D$ became available, which allows to adapt $3 \mathrm{~d}$ mesh models to the individually identified measures and curvature.

This extension is currently available as a plug-in for the professional $3 \mathrm{~d}$-software package Final Surface $^{\circledR}$ [11]. The solution works with prefabricated, designed human body models of different type (cf. [8]) and standard sizes. Based on the data set imported from BodyFit 3D, body measures as well as position and curvature of characteristic surface areas are adapted to the individual being measured, which results in nearly accurate client body avatars (head, face, hairs etc. excluded).

These avatars are provided with anatomy-like skeletons and may be positioned and even animated (fig.9). For more information please refer to [10].

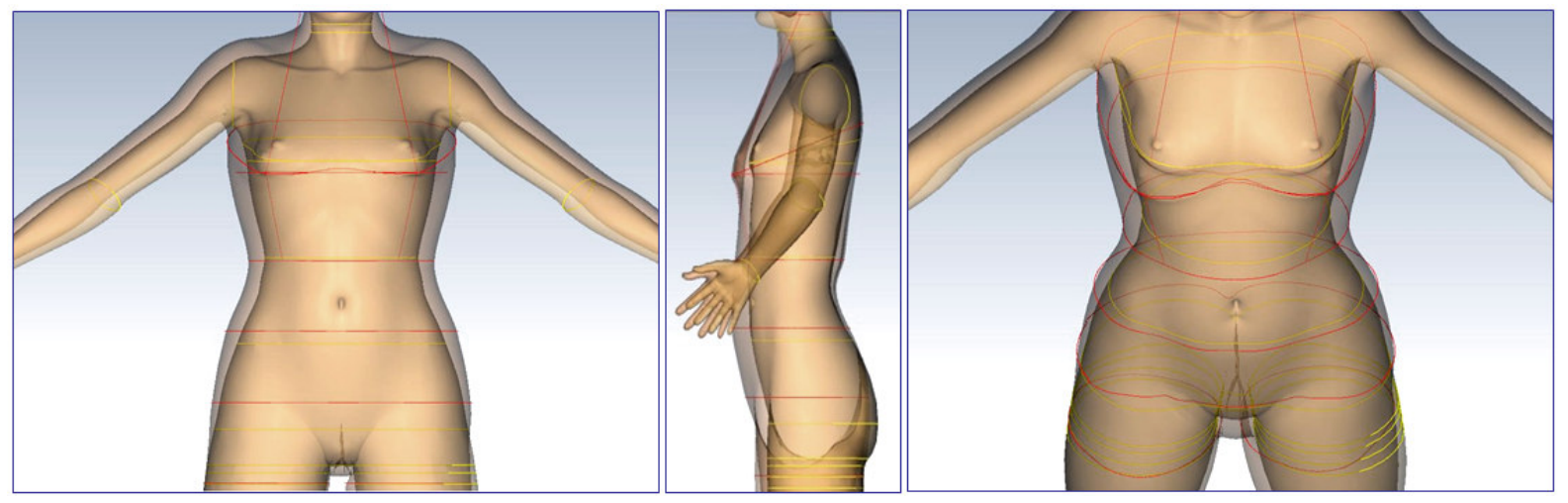

Fig. 9: avatar adjustment to BodyFit 3D data

\section{Conclusions}

The present paper introduces our developments for individual body parameter acquisition and some useful and practical extensions which are currently started to be used in practice under the label BodyFit 3D. Advantages of the system we see in:

- very short (compared to scanning procedures) measurement time,

- usage of mostly standard hardware components (low capital investment)

- no moving parts, no laser, low wear and high reliability

- selective parameter recording, compact and compatible to CAD systems

- very high automation degree

- user-friendly, ergonomic and widely accepted procedure.

The presented solutions afford objective and reproducible recording of individual geometric body parameters. By means of BodyFit 3D systems currently more than 2.000 people of different age and gender were measured. In nearly all cases the users stated about a very convenient and comprehendible workflow and a good feel after they completed the procedure. In only a few cases additional explanation or assistance was requested.

We continue to improve and enlarge BodyFit $3 D$ systems by adding new parameters, improving reliability of identification and parameter accuracy. We plan to push further modularization and diversification for particular tasks and application areas. 
In our understanding, the available, nearly full automated and relatively low-priced cabin systems recommend themselves not only for serial measurements but mainly for integrated operation in department stores, pedestrian areas and generally in the sphere of garment trade.

\section{Acknowledgments}

The involved collaborators hereby express their gratitude to the German Federal Ministry of Economics and Technology (BMWi) and Federal Ministry of Education and Research (BMBF), which had supported the presented work during several funded projects in the years 2000-2006. Currently work on BodyFit 3D extensions targeting individual jeans and trouser manufacturing is supported by an application oriented project funded by German Federal Ministry of Economics and Technology (BMWi) and financed via Euronorm GmbH (grant IW091094).

\section{References}

[1] L. Paul, N. Heuwold: Bestimmung konstruktions-kompatibler Körpermaße und unscharfer Zusatzinformationen mit automatischen Meßkabinen des Typs BodyFit 3D. Jahrbuch 2006 Optik und Feinmechanik. Herausgeber Dr.-Ing W. Prenzel. Schiele \& Schön 2006. ISBN: 3-7949-0726-4

[2] N. Heuwold, L. Paul: BodyFit3D - Körpervermessung als Baustein in der technologischen Kette der industriellen textilen Maßkonfektion. 3D-NordOst. 7. Anwenderbezogener Workshop zur Erfassung, Verarbeitung und Auswertung von 3D Daten. Tagungsband. GFal Berlin, Dez.2004, ISBN: 3-9809212-12

[3] N. Heuwold, L. Paul: Aktuelle Ansätze und Lösungen zur berührungslosen Körpermaßerfassung unter dem Aspekt der Realisierung von automatischen Meßkabinen. 3D-Nord-Ost-Tagungsband. Berlin 2002, ISBN: 3-9807029-8-7

[4] L. Paul, G. Wilde: Neue Bausteine der automatisierten industriellen Maßkonfektion, Perspektiven für Produzenten, Facheinzel- und Versandhandel. Fachzeitschrift melliand Textilberichte / Heft 1/2004

[5] T. Luhmann: Nahbereichsphotogrammetrie - Grundlagen, Methoden und Anwendungen. Herbert Wichmann Verlag, Heidelberg, 2000

[6] A. Seidl, S. Mecheels, G. Wauer, W. Bruder (Hrsg.): Zukunft Maßkonfektion. Deutscher Fachverlag, Frankfurt a. M., 2001

[7] M. Stenschke: Realisierung einer automatischen Klassifizierung von Körpertypen aus Meßdaten einer automatischen 3D-Meßkabine für die industrielle Maßkonfektion von Oberbekleidung. Diplomarbeit FHTW Berlin, Angewandte Informatik. 2004

[8] K. Kosse: Einbindung von Messdaten und vorklassifizierten Körpertypen in das CAD-System GRAFIS. Diplomarbeit FHTW Berlin, FB 5 Studiengang Bekleidungstechnik, Berlin 2006

[9] http://www.gfai.de/forschungsbereiche/3d/3ddv/InfoMaterial_BodyFit

[10] V. Kleban, L. Paul: 3D Modeling and Size Adaptation Of Individual Human Body Avatars from Parametric Measurement Data for 3D Construction and Analysis Tasks. Intern. conference on 3D Body Scanning Technologies, Lugano Oct. 2010, to be published

[11] http://www.finalsurface.de 